\title{
ZACHOWANIA ZDROWOTNE STUDENTEK PIELĘGNIARSTWA W POLSCE I NA ŁOTWIE
} HEALTH-RELATED BEHAVIOURS IN STUDENTS OF NURSING IN POLAND AND LATVIA

\author{
Marta Mandziuk $\mathbf{k}^{1(\mathrm{~A}, \mathrm{~B}, \mathrm{C}, \mathrm{D}, \mathrm{E}, \mathrm{F}, \mathrm{G})}$
}

${ }^{1}$ Państwowa Szkoła Wyższa im. Papieża Jana Pawła II w Białej Podlaskiej

\author{
Mandziuk, M. (2017). Zachowania zdrowotne studentek pielęgniarstwa w Polsce i na Łotwie. Rozprawy Społeczne, 11(4), 50-55. \\ https://doi.org/10.29316/rs.2017.38
}

Wkład autorów:

A. Zaplanowanie badań

B. Zebranie danych

C. Dane - analiza i statystyki

D. Interpretacja danych

E. Przygotowanie artykułu

F. Wyszukiwanie i analiza

literatury

G. Zebranie funduszy
Tabele: 4

Ryciny: 1

Literatura: 25

Otrzymano: czerwiec 2017

Zaakceptowano: listopad 2017

\begin{abstract}
Streszczenie
Wstęp. Celem artykułu jest ukazanie stopnia nasilenia zachowań zdrowotnych studentek pielęgniarstwa w Polsce i na Łotwie.

Materiał i metody. Badaniem objęto 140 studentek, w tym 65 z Polski i 75 z Łotwy. Narzędziem badawczym był Inwentarz Zachowań Zdrowotnych wg. Juczyńskiego. Dokonano pomiarów wysokości i masy ciała celem obliczenia wskaźnika BMI.

Wyniki. U większości polskich studentek $(49,84 \%)$ odnotowano niski poziom nasilenia zachowań zdrowotnych, natomiast wśród Łotyszek większością $(45,33 \%)$ były te z wynikiem świadczącym o przeciętnym stopniu nasilenia zachowań sprzyjających zdrowiu. Studentki z Polski charakteryzował istotnie statystycznie wyższy poziom nasilenia prawidłowych nawyków żywieniowych niż studentki z Łotwy $(\mathrm{p}=0,02)$. Porównując $\mathrm{z}$ wynikami grupy standaryzowanej wykazano istotne statystycznie różnice $w$ trzech kategoriach zachowań zdrowotnych: w zakresie prawidłowych nawyków żywieniowych ( $\mathrm{p}=0,001$ dla Łotwy i Polski), pozytywnego nastawienia psychicznego $(\mathrm{p}=0,01$ Łotwa; $\mathrm{p}=0,04$ Polska) oraz praktyk zdrowotnych $(\mathrm{p}=0,001$ 七otwa; $p=0,03$ Polska).

Wnioski. Uzyskane wyniki wskazują na potrzebę monitorowania zachowań zdrowotnych celem
\end{abstract} zapobiegania rozwojowi chorób cywilizacyjnych.

Słowa kluczowe: studenci, zachowania zdrowotne, Inwentarz Zachowań Zdrowotnych

\section{Summary}

Introduction. The article aims to present the degree of health-related behaviour in female students of nursing in Poland and Latvia.

Material and methods. The study involved 140 female students, with 65 coming from Poland and 75 from Latvia. The applied research tool was The Health Care Inventory designed by Juczyński. Height and weight were also measured to calculate the BMI.

Results. The majority of the Polish female students (49.84\%) were reported to demonstrate a low level of health-related behaviour, while the majority Latvians, i.e. $45.33 \%$, represented an average level of such a behaviour. Statistically, the Polish female students showed a significantly higher level of appropriate dietary habits than the Latvian ones ( $p=0.02)$. In comparisons to the standardised group's results, there were significant statistical differences in three categories of health-related behaviours: in the area of appropriate dietary habits ( $p=0.001$ for Latvia and Poland), positive mental attitude ( $p=0.01$ Latvia, $p=0.04$ Poland) and health-related practices $(p=0.001$ Latvia; $p=0.03$ Poland).

Conclusions. The obtained results indicate that there is a need of monitoring health-related behaviours in future nurses to prevent the development of civilisation diseases.

Keywords: students, pro-health behaviour, Health Behaviour Inventory

\section{Wstęp}

Zachowania zdrowotne są istotnym czynnikiem warunkującym utrzymanie dobrego stanu zdrowia do późnych lat życia. Można je zdefiniować, jako wszelkie formy zachowań podejmowanych przez jednostkę i grupy społeczne, odnoszące pozytywny bądź negatywny wpływ na zdrowie (Zadworna-Cieślak, 2011). Wzory zachowań zdrowotnych oraz ich nasilenie są elementem procesów socjalizacyjnych człowieka (Heszen, 2007; Zadworna-Cieślak, 2010). Czynnikami determinującymi określone zachowania zdrowotne są m.in. płeć, wykształcenie, sytuacja społeczna i ekonomiczna (Heszen, 2007; Bisop, 2007; Dolińska-Zygmunt, 2000; Fukuda, Nakamura, Takano, 2005). Wiek należy także do predykatorów zachowań zdrowotnych, które wraz z wydłużaniem się życia zmieniają swój charakter.

Zachowania zdrowotne kształtują się w każdym etapie życia, ale pierwszym poważnym sprawdzia-

Adres korespondencyjny: Marta Mandziuk, Państwowa Szkoła Wyższa im. Papieża Jana Pawła II w Białej Podlaskiej, ul. Sidorska 105, 21-500 Biała Podlaska, e-mail: m.mandziuk@dydaktyka.pswbp.pl,tel.: 833449900

Copyright by: Państwowa Szkoła Wyższa im. Papieża Jana Pawła II w Białej Podlaskiej, Marta Mandziuk

Czasopismo Open Access, wszystkie artykuły udostępniane są na mocy licencji Creative Commons Uznanie autorstwa-użycie niekomercyjne-na tych samych warunkach 4.0 Międzynarodowe (CC BY-NC-SA 4.0, http://creativecommons.org/licenses/by-nc-sa/4.0/). 
nem ich trwałości jest okres studiów, które najczęściej odbywają się poza miejscem zamieszkania. Romanowska-Tołłoczko (2011) zwraca uwagę, iż zachowania zdrowotne są formowane i umacniane głównie w drugiej i trzeciej dekadzie życia, a więc wtedy gdy młodzież podejmuje ważne dla niej decyzje. Okres studiów to czas, w którym młodzież rozpoczyna „dorosłe" życie, poza nauką, musi odnaleźć się w nowej rzeczywistości, tj. zapewnić sobie mieszkanie, posiłek, dostęp do lekarza i wiele innych niezbędnych rzeczy. Daleko od domu rodzinnego, brak nadzoru, ale też brak wskazówek i pomocy ze strony rodziców, zachłyśnięcie się „wolnością”, pierwsze niepowodzenia, itp., mogą przyczynić się do podejmowania lub umacniania zachowań ryzykownych dla zdrowia. Życie akademickie jest pełne ciekawych przygód, ale też rządzi się swoimi prawami, które w większości, nie służą utrzymaniu zdrowia, $\mathrm{m}$. in. nieprawidłowe odżywianie się, niska aktywność fizyczna, oddziaływanie stresu, eksperymentowanie z różnego rodzaju używkami (Łaszek, Nowacka, Gawron-Skarbek, Szatko, 2011). W procesie kształtowania zachowań zdrowotnych i ich podejmowania zdaniem Ślusarskiej, Kulik, Piaseckiej i Pacian, (2012) istotna jest zarówno wiedza o zdrowiu, jak też pełnione role społeczne i zawodowe. Szczególny niepokój mogą budzić niekorzystne dla zdrowia zachowania studentów kierunków medycznych - osób o wyższej niż przeciętna świadomości zdrowotnej, przyszłych lekarzy, pielęgniarki itp. (Choi Won, Harris, Okuyemik, 2003; Walentukiewicz, Łysak, Wilk 2013). Celem badań była ocena nasilenia zachowań zdrowotnych studentek pielęgniarstwa w Polsce i na Łotwie.

\section{Materiał i metody}

W badaniach udział wzięły studentki pielęgniarstwa, które z racji wybranego kierunku studiów i zawodu ściśle związanego ze zdrowiem powinny odznaczać się wysokim poziomem zachowań zdrowotnych. Pracując w przyszłości z zawodzie jednym z wielu ich zadań będzie edukacja zdrowotna pacjentów i zachęcanie ich do podejmowania zachowań sprzyjających zdrowiu. Badania przeprowadzono w październiku 2016 roku wśród studentek pielęgniarstwa Państwowej Szkoły Wyższej w Białej Podlaskiej i Riga Medical College of the University of Latvia. Rozdano 165 ankiet, po wstępnej analizie ich kompletności, do dalszego postępowania zakwalifikowano 140, co stanowiło $84,85 \%$ wszystkich badanych (65 studentek z Polski $(46,43 \%)$ i 75 z Łotwy $(53,57 \%))$. Wiek badanych pochodzących z Łotwy zawierał się w przedziale 19-55 lat $(\mathrm{M}=32,71 ; \mathrm{SD}=10,64)$, a pochodzących z Polski - 18-38 lat $(M=22,43 ; S D=3,88)$. Wartość wskaźnika BMI pokazała, iż większość badanych zarówno Polek (67,7\%), jak też Łotyszek (57,3\%) odznaczała się masą ciała wagą w normie. Więcej studentek z Łotwy, niż z Polski miało nadwagę (odpowiednio: 37,3\% i 26,2\%), zaś niedowagę odnotowano u 5,3\% Łotyszek i 6,2\% Polek.
Zastosowano metodę sondażu diagnostycznego, wykorzystując technikę ankiety, w której narzędziem badawczym był standaryzowany kwestionariusz Inwentarz Zachowań Zdrowotnych (IZZ) wg. Z. Juczyńskiego (Juczyński, 2009). IZZ to kwestionariusz służący do oceny nasilenia zachowań zdrowotnych zawierający 24 stwierdzenia opisujące różnego rodzaju zachowania związane ze zdrowiem i 25-te opatrzone mianem „inne”, w którym badani mogli wpisywać własne uwagi. Wypełniając kwestionariusz respondent zaznaczał, wg ustalonej skali, częstość wykonywania określonych czynności biorąc pod uwagę ostatni rok. Suma uzyskanych punktów określa ogólny wskaźnik nasilenia zachowań zdrowotnych, którego wartości mieszczą się w granicach 24-120 punktów.Większa liczba punktów oznacza wyższy poziom nasilenia deklarowanych zachowań zdrowotnych. Otrzymany wynik, zgodnie z sugestią autora IZZ, przelicza się na jednostki standaryzowane $\mathrm{w}$ skali stenowej, przyjmując następujące przedziały: od 1 do 4 stena - niski poziom nasilenia zachowań zdrowotnych, zaś od 7 do 10 - wysoki. Wyniki dla każdej z czterech kategorii oblicza się oddzielnie. Uwzględniając wskazaną przez badanych częstotliwość poszczególnych zachowań otrzymano wynik określający ogólne nasilenie zachowań zdrowotnych oraz stopień nasilenia czterech kategorii zachowań zdrowotnych:

- prawidłowych nawyków żywieniowych, związanych głównie z rodzajem spożywanej żywności (np.: częstość spożywania pieczywa pełnoziarnistego, warzyw i owoców, unikaniem soli, tłuszczów i żywności z konserwantami);

- zachowań profilaktycznych, dotyczących przestrzegania zaleceń zdrowotnych $w$ zdrowiu i w chorobie oraz pozyskiwania informacji o sposobach unikania chorób;

- praktyk zdrowotnych, obejmujących codzienne nawyki związane ze snem, odpoczynkiem, ograniczaniem używek i aktywnością fizyczną;

- pozytywnego nastawienia psychicznego, związanego z unikaniem zbyt silnych emocji, stresów i napięć.

Pomiary antropometryczne, tj. wysokość i masę ciała, wykonano zgodnie z techniką Martina i Sallera. Uzyskane dane posłużyły do obliczenia wskaźnika masy ciała (BMI). Uwzględniając wartość wskaźnika BMI wśród badanych wyodrębniono trzy grupy: badane $\mathrm{z}$ niedowagą, $\mathrm{z}$ wagą $\mathrm{w}$ normie i $\mathrm{z}$ nadwagą lub otyłością (Cole, Bellizzi, Flegal, Dietz, 2000; Cole, Flegal, Nicholls, Jackson, 2007).

Zebrane dane poddano analizie statystycznej w programie SPSS Statistica 23.0. Istotność wyników przyjęto na poziomie $\alpha=0,05$. Stwierdzono, że wyniki zawierają się w rozkładzie normalnym i w związ$\mathrm{ku}$ z tym pozwoliło to na zastosowanie w dalszych analizach procedur parametrycznych tj. testu t-Studenta dla jednej i dwóch prób niezależnych oraz analizy wariancji ANOVA. 


\section{Wyniki}

Wyniki badań wskazują, że ogólny wskaźnik nasilenia zachowań zdrowotnych studentek z obu badanych państw jest na zbliżonym poziomie (Tabela 1.). Analizując poszczególne kategorie zachowań zdrowotnych zauważono, iż w kategorii prawidłowych nawyków żywieniowych, zachowaniach profilaktycznych i praktykach zdrowotnych stopień nasilenia jest na wyższym poziomie u polskich studentek niż u łotewskich. Natomiast studentki z Łotwy odznaczały się wyższym stopniem nasilenia zachowań zdrowotnych w kategorii pozytywnego nastawienia psychicznego.

Tabela 1. Ogólny wskaźnik nasilenia zachowań zdrowotnych studentek pielęgniarstwa w Polsce i na Łotwie

\begin{tabular}{|l|l|c|c|c|c|c|c|c|c|}
\hline & & $\boldsymbol{N}$ & $\boldsymbol{M}$ & $\boldsymbol{M e}$ & $\boldsymbol{S D}$ & Skośność & Kurtoza & Min & Max \\
\hline Zachowania zdrowotne (ogółem) & Łotwa & 75 & 77,95 & 79 & 12,09 & $-0,36$ & $-0,36$ & 48 & 100 \\
\hline & Polska & 65 & 78,08 & 76 & 11,58 & 0,60 & $-0,12$ & 57 & 107 \\
\hline Prawidłowe nawyki żywieniowe & Łotwa & 75 & 18,63 & 20 & 4,34 & $-0,10$ & $-0,33$ & 10 & 28 \\
\hline & Polska & 65 & 20,54 & 20 & 5,11 & 0,33 & $-0,64$ & 11 & 32 \\
\hline Zachowania profilaktyczne & Łotwa & 75 & 19,69 & 20 & 3,71 & $-0,12$ & $-0,01$ & 12 & 29 \\
\hline & Polska & 65 & 19,75 & 20 & 4,24 & $-0,04$ & $-0,35$ & 10 & 29 \\
\hline Pozytywne nastawienie psychiczne & Łotwa & 75 & 21,35 & 21 & 3,83 & $-0,13$ & $-0,61$ & 13 & 29 \\
\hline & Polska & 65 & 20,85 & 21 & 3,68 & $-0,14$ & $-0,30$ & 13 & 28 \\
\hline Praktyki zdrowotne & Łotwa & 75 & 18,28 & 18 & 3,47 & 0,06 & $-0,36$ & 11 & 27 \\
\hline & Polska & 65 & 19,34 & 20 & 3,86 & $-0,12$ & $-0,56$ & 10 & 27 \\
\hline
\end{tabular}

$N$ - liczebność, $M$ - średnia, $M e$ - mediana, $S D$ - odchylenie standardowe, $M i n$ - minimum, Max - maksimum

Po przeliczeniu na skalę stenową zauważono, iż prawie połowa ogółu badanych $(48,57 \%)$ uzyskała wynik w przedziale 1-4 stena, co wskazuje na niski stopień nasilenia zachowań sprzyjających zdrowiu, natomiast wynik świadczący o wysokim stopniu nasilenia zachowań, tj. powyżej 6 stena uzyskało tylko $12,14 \%$. Analizując dane dla poszczególnych krajów

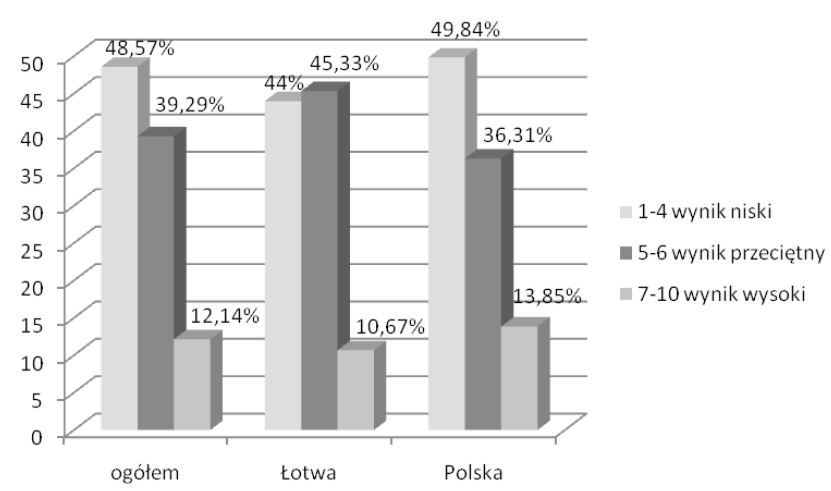

Rycina 1. Ogólny wskaźnik stopnia nasilenia zachowań zdrowotnych badanych w skali stenowej

W dalszej części analizy dokonano porównania zachowań zdrowotnych ogółem i poszczególnych kategorii zachowań między badanymi państwami (Tabela 2.). Stwierdzono istotne statystycznie różnice w kategorii prawidłowych nawyków żywieniowych $(\mathrm{p}=0,02)$. Studentki pielęgniarstwa z Polski charakteryzował wyższy stopień nasilenia prawidłowych nawyków żywieniowych $(20,54-18,63)$. W pozostałych kategoriach zachowań zdrowotnych badane grupy nie różniły się. zauważono, iż zarówno w Polsce, jak i na Łotwie wysoki wynik uzyskała najmniejsza grupa badanych (odpowiednio: $13,85 \%$ i $10,67 \%$ ). Wśród polskich studentek większością były te, których ogólny wskaźnik nasilenia zachowań zdrowotnych był niski $(49,84 \%)$, natomiast największą grupę wśród Łotyszek stanowiły te $\mathrm{z}$ wynikiem przeciętnym $(45,33 \%)$ (Rycina 1.).

Tabela 2. Porównanie zachowań zdrowotnych studentek pielęgniarstwa w Polsce i na Łotwie

\begin{tabular}{|l|c|c|c|c|c|c|}
\hline \multirow{2}{*}{} & \multicolumn{2}{|c|}{ Łotwa } & \multicolumn{2}{c|}{ Polska } & & \\
\cline { 2 - 7 } & $\boldsymbol{M}$ & $\boldsymbol{S D}$ & $\boldsymbol{M}$ & $\boldsymbol{S D}$ & $\boldsymbol{t}(\mathbf{1 3 8 )}$ & $\boldsymbol{p}$ \\
\hline $\begin{array}{l}\text { Zachowania zdrowotne } \\
\text { (ogółem) }\end{array}$ & 77,95 & 12,09 & 78,08 & 11,58 & $-0,06$ & 0,95 \\
\hline $\begin{array}{l}\text { Prawidłowe nawyki } \\
\text { żywieniowe }\end{array}$ & 18,63 & 4,34 & 20,54 & 5,11 & $-2,39$ & $\mathbf{0 , 0 2} *$ \\
\hline $\begin{array}{l}\text { Zachowania } \\
\text { profilaktyczne }\end{array}$ & 19,69 & 3,71 & 19,75 & 4,24 & $-0,09$ & 0,93 \\
\hline $\begin{array}{l}\text { Pozytywne nastawienie } \\
\text { psychiczne }\end{array}$ & 21,35 & 3,83 & 20,85 & 3,68 & 0,79 & 0,43 \\
\hline Praktyki zdrowotne & 18,28 & 3,47 & 19,34 & 3,86 & $-1,71$ & 0,09 \\
\hline
\end{tabular}

* zależność istotna statystycznie

Otrzymane wyniki deklarowanych zachowań zdrowotnych studentek pielęgniarstwa w Polsce i na Łotwie porównano $\mathrm{z}$ wynikami grupy standaryzowanej (Tabela 3.) (Juczyński, 2009). Przeprowadzona analiza pozwoliła stwierdzić istotne statystycznie różnice w zakresie prawidłowych nawyków żywieniowych, pozytywnego nastawienia psychicznego oraz praktyk zdrowotnych. Zaobserwowano także różnice na poziomie tendencji statystycznej w zakresie ogólnych zachowań zdrowotnych $(p<0,10)$. U badanych studentek z obu państw stwierdzono niższy, 
niż w grupie standaryzowanej, ogólny wskaźnik nasilenia zachowań zdrowotnych. Nie stwierdzono istotnych różnic jedynie w zakresie zachowań profilaktycznych.

Tabela 3. Porównanie zachowań zdrowotnych studentek pielęgniarstwa w Polsce i na Łotwie z wynikami standaryzowanymi

\begin{tabular}{|c|c|c|c|c|c|c|}
\hline & & $\begin{array}{c}\text { Wynik } \\
\text { grup badanych }\end{array}$ & $\begin{array}{c}\text { Wynik } \\
\text { standaryzowany }\end{array}$ & $t$ & $d f$ & $p$ \\
\hline \multirow[t]{2}{*}{ Zachowania zdrowotne (ogółem) } & Łotwa & 77,95 & \multirow{2}{*}{80,62} & $-1,92$ & 74 & $0,06^{*}$ \\
\hline & Polska & 78,08 & & $-1,77$ & 64 & $0,08^{*}$ \\
\hline \multirow[t]{2}{*}{ 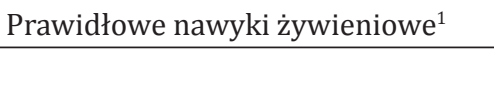 } & Łotwa & 3,10 & \multirow{2}{*}{3,45} & $-4,14$ & 74 & $0,001^{*}$ \\
\hline & Polska & 3,02 & & $-4,63$ & 64 & $0,001^{*}$ \\
\hline \multirow[t]{2}{*}{ Zachowania profilaktyczne $^{1}$} & Łotwa & 3,28 & \multirow{2}{*}{3,22} & 0,87 & 74 & 0,39 \\
\hline & Polska & 3,29 & & 0,82 & 64 & 0,41 \\
\hline \multirow[t]{2}{*}{ Pozytywne nastawienie psychiczne ${ }^{1}$} & Łotwa & 3,56 & \multirow{2}{*}{3,36} & 2,69 & 74 & $0,01^{*}$ \\
\hline & Polska & 3,47 & & 1,50 & 64 & $0,04^{*}$ \\
\hline \multirow[t]{2}{*}{ Praktyki zdrowotne $^{1}$} & Łotwa & 3,05 & \multirow{2}{*}{3,40} & $-5,29$ & 74 & $0,001^{*}$ \\
\hline & Polska & 3,22 & & $-2,22$ & 64 & $0,03^{*}$ \\
\hline
\end{tabular}

${ }^{1}$ Na potrzeby porównania uśredniono wartości zmiennych

*zależność istotna statystycznie

Analiza deklarowanych zachowań zdrowotnych studentek pielęgniarstwa z Polski i Łotwy w zależności od wartości wskaźnika masy ciała BMI wykazała w obu badanych grupach brak istotnych statystycznie róż- nic międzygrupowych w zakresie ogólnych zachowań zdrowotnych i poszczególnych kategoriach zachowań (Tabela 4.).

Tabela 4. Porównanie zachowań zdrowotnych studentek pielęgniarstwa w Polsce i na Łotwie w zależności od wielkości wskaźnika BMI

\begin{tabular}{|c|c|c|c|c|c|c|c|c|c|c|c|}
\hline & & \multicolumn{2}{|c|}{ Nadwaga } & \multicolumn{2}{|c|}{ Niedowaga } & \multicolumn{2}{|c|}{ Norma } & \multirow[b]{2}{*}{$\begin{array}{c}\text { Testy } \\
\text { post hoc }\end{array}$} & \multirow[b]{2}{*}{$\boldsymbol{F}$} & \multirow[b]{2}{*}{$d f$} & \multirow[b]{2}{*}{$p$} \\
\hline & & $M$ & $S D$ & $M$ & $S D$ & $M$ & $S D$ & & & & \\
\hline \multirow[t]{2}{*}{ Zachowania zdrowotne (ogółem) } & Łotwa & 77,46 & 10,97 & 68,00 & 11,05 & 79,19 & 12,66 & - & 1,63 & 2,72 & 0,20 \\
\hline & Polska & 76,94 & 9,60 & 83,25 & 8,85 & 78,05 & 12,52 & - & 0,47 & 2,62 & 0,63 \\
\hline \multirow[t]{2}{*}{ Prawidłowe nawyki żywieniowe } & Łotwa & 18,21 & 3,37 & 14,50 & 2,52 & 19,28 & 4,82 & - & 2,52 & 2,72 & 0,09 \\
\hline & Polska & 19,41 & 4,12 & 20,50 & 5,92 & 20,98 & 5,42 & - & 0,57 & 2,62 & 0,57 \\
\hline \multirow[t]{2}{*}{ Zachowania profilaktyczne } & Łotwa & 20,25 & 3,98 & 16,75 & 3,30 & 19,60 & 3,50 & - & 1,61 & 2,72 & 0,21 \\
\hline & Polska & 20,82 & 4,00 & 22,75 & 0,96 & 19,07 & 4,36 & - & 2,19 & 2,62 & 0,12 \\
\hline \multirow[t]{2}{*}{ Pozytywne nastawienie psychiczne } & Łotwa & 21,11 & 3,61 & 19,25 & 4,72 & 21,70 & 3,90 & - & 0,83 & 2,72 & 0,44 \\
\hline & Polska & 20,94 & 3,61 & 21,50 & 3,00 & 20,75 & 3,83 & - & 0,08 & 2,62 & 0,92 \\
\hline \multirow[t]{2}{*}{ Praktyki zdrowotne } & Łotwa & 17,89 & 2,99 & 17,50 & 4,65 & 18,60 & 3,70 & - & 0,46 & 2,72 & 0,64 \\
\hline & Polska & 18,12 & 3,50 & 21,50 & 1,29 & 19,61 & 4,05 & - & 1,62 & 2,62 & 0,21 \\
\hline
\end{tabular}

\section{Dyskusja}

Na podstawie przeglądu badań dotyczących zachowań zdrowotnych młodzieży studiującej można stwierdzić, iż są one na niezadowalającym poziomie (Lewko, Potylińska-Lewko, Sierakowska, Krajewska-Kułak, 2003; Walentukiewicz, Łysak, Wilk, 2013; Kropornicka i in. 2015; Kuriańska-Wołoszyn, Wołoszyn, 2016). Potwierdzają to także wyniki badań własnych, w których prawie połowa badanych $(48,57 \%)$ uzyskała wynik (w przedziale $1-4$ stena) wskazujący na niski poziom nasilenia zachowań sprzyjających zdrowiu, natomiast u 39,29\% respondentów odnotowano wynik przeciętny (5-6 sten), a tylko $12,14 \%$ badanych otrzymało wynik powyżej 6 stena, tzn. wysoki poziom zachowań zdrowotnych (Rycina 1.). Zbliżone wyniki dostrzeżono wśród białostockich studentów (Politechnika i Uniwersytet Medyczny), wśród których 46,4\% badanych odznaczało się niskim poziomem wskaźnika nasilenia zachowań zdrowotnych (1-4 sten), zaś 45,5\% wynikiem przeciętnym (5-6 sten), a tylko 8,1\% wysokim (powyżej 7 stena) (Kulesza-Bronczyk, Dobrzycka, Sobieranska, Korzeniecka-Kozerska, Terlikowski, 
2014). Znacznie wyższy poziom wskaźnika nasilenia zachowań zdrowotnych uzyskali studenci bydgoskich szkół wyższych: dietetyki - 8,32 stena i fizjoterapii - 6,64, co wskazuje na wysoki wynik (Weber-Rajek i in., 2015). Porównując średnie wyniki ogólnych zachowań zdrowotnych, zarówno studentek z Polski $(78,08)$, jak też z Łotwy $(77,95)$ z danymi uzyskanymi przez innych badaczy stwierdzono, że są one na zbliżonym poziomie (77,6 - (Kulesza-Bronczyk i in., 2014), 78,025 - (Palacz 2014), 77,4- (Rasińska, 2012). Nieco niższy $(73,19)$ ogólny wskaźnik nasilenia zachowań zdrowotnych uzyskali studenci pielegniarstwa $\mathrm{w}$ badaniach Walentukiewicz $\mathrm{i}$ in (2013). Znacznie wyższy ogólny wskaźnik zachowań sprzyjających zdrowiu uzyskały studentki dietetyki $(84,05)$ (Nowak, Żelazko, Rogalska, Nowak i Pawlas, 2016). Analizując poszczególne kategorie zachowań zdrowotnych zauważono (Tabela 2.), iż najniższa średnią uzyskały studentki w zakresie praktyk zdrowotnych (Łotwa 18,28 i Polska 19,34). Najwyższą zaś w kategorii pozytywnego nastawienia psychicznego (Łotwa 21,35 i Polska 20,85). Niniejsze wyniki potwierdzają otrzymane przez Walentukiewicz i in. (2013). Inne rezultaty otrzymała Palacz (2014), odnotowując najniższą średnią deklarowanych zachowań zdrowotnych w zakresie prawidłowych nawyków żywieniowych $(18,792)$ oraz najwyższą w kategorii pozytywnego nastawienia psychicznego $(20,986)$. Porównując deklarowane zachowania zdrowotne studentek z Polski i Łotwy stwierdzono istotne statystycznie różnice $\mathrm{w}$ zakresie prawidłowych zachowań żywieniowych na korzyść polskich studentek $(\mathrm{p}=0,02)$ (Tabela 2.). Analizując zależności między wynikami badań własnych a wynikami grupy standaryzowanej wykazano istotne statystycznie różnice w trzech z czterech kategorii zachowań zdrowotnych: w zakresie prawidłowych nawyków żywieniowych ( $p=0,001$ dla Łotwy i Polski), pozytywnego nastawienia psychicznego ( $p=0,01$ Łotwa; $p=0,04$ Polska) oraz praktyk zdrowotnych ( $p=0,001$ Łotwa; $\mathrm{p}=0,03$ Polska) (Tabela 3.) (Juczyński, 2009). Zaobserwowano także różnice na poziomie tendencji statystycznej w zakresie zachowań zdrowotnych w ujęciu ogólnym $(\mathrm{p}<0,10)$. Nie stwierdzono istotnych różnic jedynie $\mathrm{w}$ zakresie zachowań profilaktycznych. Badane zarówno z Łotwy, jak też z Polski uzyskały niższe wyniki w porównaniu do grupy standaryzowanej w zakresie prawidłowych nawyków żywieniowych (3,10 Łotwa; 3,02 Polska; grupa porównawcza
3,45) i praktyk zdrowotnych (odpowiednio: 3,05; $3,22 ; 3,40)$. W pozostałych kategoriach wyniki badań własnych były wyższe. Wyniki badań własnych znajdują potwierdzenie u innych autorów (Rasińska, 2012; Rasińska, Nowakowska, Nowomiejski, 2013; Ślusarska, Zarzycka, Wrońska, 2015). Ponadto Ślusarska i in. (2015) wykazały, iż studenci kierunków medycznych odznaczają się wyższym wskaźnikiem nasilenia zachowań zdrowotnych w większości kategorii (oprócz praktyk zdrowotnych), niż studenci kierunków niemedycznych. Wyniki badań własnych wykazały brak istotnych statystycznie różnic między studentkami z Łotwy i Polski a ich wartością wskaźnika BMI. Walentukiewicz i in. (2013) także nie odnotowała statystycznie istotnych różnic w zachowaniach zdrowotnych uczennic o różnej wartości wskaźnika BMI.

W odniesieniu do młodzieży akademickiej wyniki badań własnych i tych obecnych w literaturze (w przeważającej większości wyniki niskie lub przeciętne) nie powinny być zaskoczeniem, ponieważ okres studiów jest jednym z najtrudniejszych w życiu. To czas próby dla wartości, postaw i zachowań zdrowotnych kształtowanych do tej pory. Dezorganizacja dnia codziennego spowodowana planem zajęć i często podejmowaną przez studentów pracą sprzyja nieregularnemu odżywianiu, ograniczeniu aktywności fizycznej i ogólnym zaniedbaniom w zakresie dbałości o zdrowie. Niemniej jednak biorąc pod uwagę kierunek studiów badanych (pielęgniarstwo) to uzyskane wyniki niepokoją, ponieważ Ci studenci, $\mathrm{z}$ jednej strony mają większą wiedzę na temat zdrowia, a z drugiej są przyszłymi kreatorami zdrowia, którzy by być wiarygodnymi powinni tę wiedzę połączyć z praktyką i swoim postępowaniem być przykładem dla innych.

\section{Wnioski}

1. Wskaźnik zachowań zdrowotnych studentek polskich był wyższy i różnił się od analogicznego wskaźnika, oznaczonego dla studentek z Łotwy.

2. W stosunku do grupy standaryzowanej studentki z obu państw uzyskały niższe wyniki ogólnego wskaźnika nasilenia zachowań zdrowotnych oraz w kategoriach: prawidłowe nawyki żywieniowe i praktyki zdrowotne, wyższe zaś w kategoriach: zachowania profilaktyczne i pozytywne nastawienie psychiczne.

\section{Literatura:}

1. Bishop, G. (2007). Psychologia zdrowia. Wrocław: Wydawnictwo Astrum.

2. Choi Won, S., Harris, K., Okuyemik, K. (2003). Predictors of smoking initiation among college-bound high school students. Annals of Behavioral Medicine, 26, 69-74.

3. Cole, TJ., Bellizzi, MC., Flegal, KM., Dietz, WH. (2000). Establishing a standard definition for child overweight and obesity worldwide: international survey. British Medical Journal, 320(7244), 1240-1243.

4. Cole, TJ., Flegal, KM., Nicholls, D., Jackson, AA. (2007). Body mass index cut offs to define thinness in children and adolescents: international survey. British Medical Journal, 335(7612), 194.

5. Dolińska-Zygmunt, G. (2000). Podmiotowe uwarunkowania zachowań promujacych zdrowie. Warszawa: Wydawnictwo Instytutu Psychologii. 
6. Fukuda, Y., Nakamura, K., Takano, T. (2005). Accumulation of health risk behaviours is associated with lower socioeconomic status and women`s urban residence: a multilevel analysis in Japan. BMC Public Health, 5, 53-58.

7. Heszen, I., Sęk, H. (2007). Psychologia zdrowia. Warszawa: PWN.

8. Juczyński, Z. (2009). Narzędzia pomiaru w promocji i psychologii zdrowia. Warszawa: Pracownia Testów Psychologicznych.

9. Kropornicka, B., Baczewska, B., Dragan, W., Krzyżanowska, E., Olszak, C., Szymczuk, E. (2015). Zachowania zdrowotne studentów Uniwersytetu Medycznego w Lublinie. Rozprawy Społeczne, 9(2), 58-64.

10. Kulesza-Bronczyk, B., Dobrzycka, B., Sobieranska, JM., Korzeniecka-Kozerska, A., Terlikowski, SJ. (2014). Health behaviors and knowledge of birth control methods among students. Progress in Health Sciences, 4(1), 136-143.

11. Kuriańska-Wołoszyn, J., Wołoszyn, A. (2016). Zachowania prozdrowotne studentek a wymagania zawodu pedagoga. W: D. Umiastowska (red.), Aktywność ruchowa ludzi w różnym wieku (s. 61-70). Szczecin: Wydawnictwo Albatros.

12. Lewko, J., Potylińska-Lewko, B., Sierakowska, M., Krajewska-Kułak, E. (2003). Zachowania zdrowotne wśród studentów pielęgniarstwa. W: Promocja zdrowia w hierarchii wartości. Lublin: Neurocentrum.

13. Łaszek, M., Nowacka, E., Gawron-Skarbek, A., Szatko, F. (2011). Negatywne wzorce zachowań zdrowotnych studentów. Część II. Aktywność fizyczna i nawyki żywieniowe. Problemy Higieny i Epidemiologii, 92(3), 461-465.

14. Nowak, G., Żelazko, A., Rogalska, A., Nowak, D., Pawlas, K. (2016). Badanie zachowań zdrowotnych i osobowości typu D wśród studentek dietetyki. Medycyna Ogólna i Nauki o Zdrowiu, 22(2), 129-134.

15. Palacz, J. (2014). Zachowania zdrowotne studentów w świetle wybranych uwarunkowań. Medycyna Ogólna i Nauki o Zdrowiu, 20(3), 301-306.

16. Rasińska, R. (2012). Nawyki żywieniowe studentów w zależności od płci. Nowiny Lekarskie, 81(4), 354359.

17. Rasińska, R., Nowakowska, I., Nowomiejski, J. (2013). Diagnoza stanu zdrowia studentów i ich opinie o zagrożeniach zdrowotnych. Pielęgniarstwo Polskie, 2(48), 79-84.

18. Romanowska-Tołłoczko, A. (2011). Styl życia studentów oceniany w kontekście zachowań zdrowotnych. Hygeia Public Health, 46(1), 89-93.

19. Ślusarska, B., Kulik, T.B., Piasecka, H., Pacian, A, (2012). Wiedza i zachowania zdrowotne studentów medycyny w zakresie czynników ryzyka sercowo-naczyniowego. Medycyna Ogólna i Nauki o Zdrowiu, 18(1), 19-26.

20. Ślusarska, B., Zarzycka, D., Wrońska, I. (2015). Zróżnicowanie behawioralnych czynników zdrowia wśród studentów zależne od wybranych wskaźników społeczno-demograficznych i środowiskowo-kulturowych. Journal of Education, Health and Sport, 2, 99-108.

21. Walentukiewicz, A., Łysak, A., Wilk, B. (2011). Uwarunkowania zdrowia gdańskich 18-latek - zachowania zdrowotne. Problemy Higieny i Epidemiologii, 92(3), 482-485.

22. Walentukiewicz, A., Łysak, A., Wilk, B. (2013). Zachowania zdrowotne studentek pielęgniarstwa. Problemy Pieleggniarstwa, 21(4), 484-488.

23. Weber-Rajek, M., Baumgart, M., Michalski, A., Radzimińska, A., Goch, A., Lulińska-Kulik, E., Zukow, W. (2015). Students' health behaviors - own research. Zachowania zdrowotne studentów - badania własne. Journal of Education, Health and Sport, 5(9), 647-662.

24. Zadworna-Cieślak, M. (2010). Zachowania zdrowotne rodziców i ich dorastających dzieci. W: N. Ogińska-Bulik (red.), Zachowania ryzykowne i szkodliwe dla zdrowia (s. 59-76). Łódź: Wydawnictwo Akademii Humanistyczno-Ekonomicznej.

25. Zadworna-Cieślak, M., Ogińska-Bulik, N. (2011). Zachowania zdrowotne młodzieży - uwarunkowania podmiotowe i rodzinne. Warszawa: Difin. 